Document downloaded from:

http://hdl.handle.net/10251/121114

This paper must be cited as:

Dalmau-Borrás, A.; Roda Buch, A.; Rovira, A.; Navarro-Laboulais, J.; Igual Muñoz, AN. (2018). Wear model for describing the time dependence of the material degradation mechanisms of the AISI 316L in a NaCl solution. Wear. 394-395:166-175. https://doi.org/10.1016/j.wear.2017.10.015

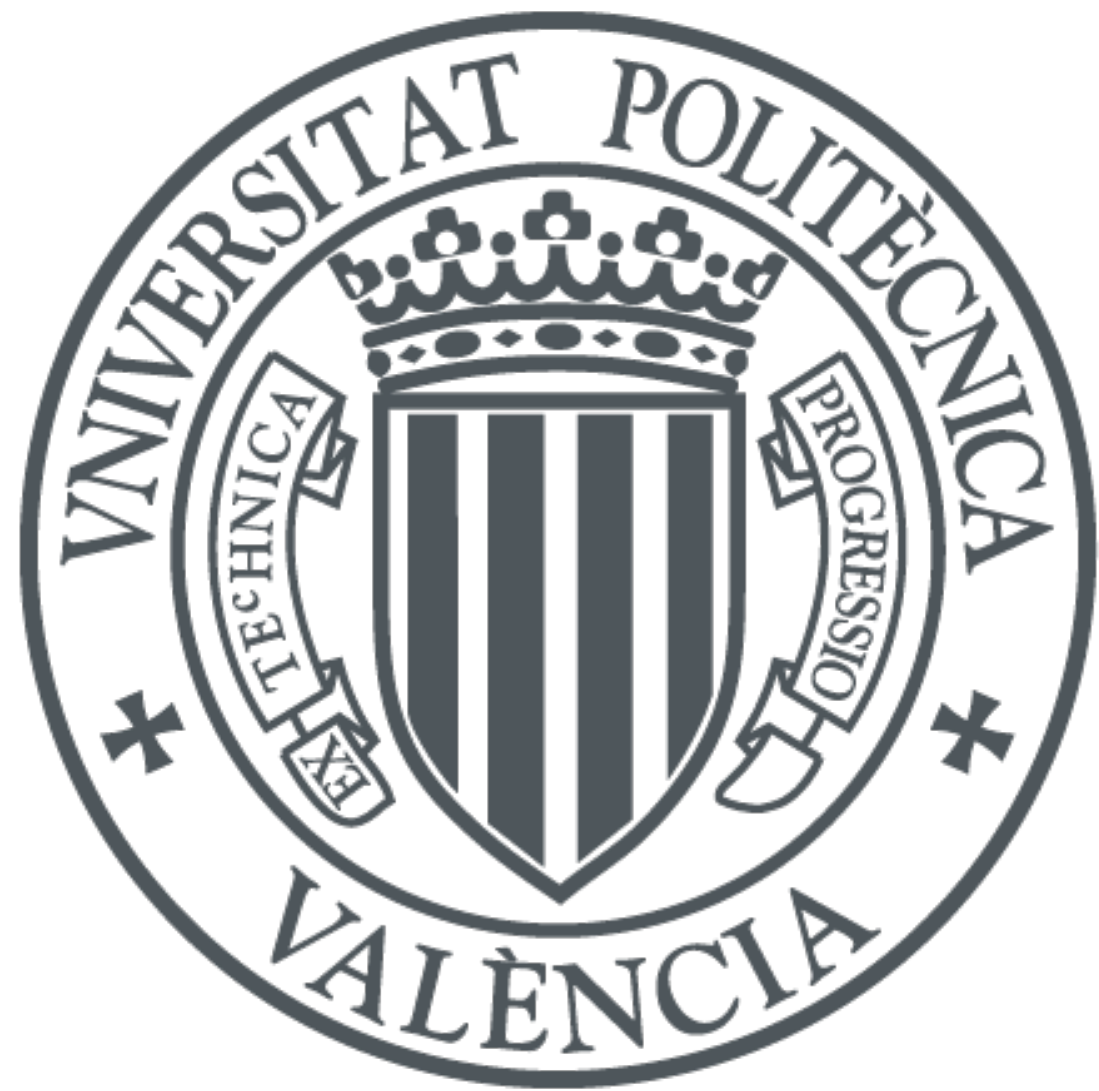

The final publication is available at

https://doi.org/10.1016/j.wear.2017.10.015

Copyright Elsevier

Additional Information 


\title{
Wear model for describing the time dependence of the material degradation mechanisms of the AISI 316 in a $\mathrm{NaCl}$ solution
}

\author{
A. Dalmau ${ }^{1}$, A. Roda Buch ${ }^{2}$, A. Rovira ${ }^{2}$, J. Navarro-Laboulais ${ }^{1}$, A. Igual Muñoz ${ }^{1,3, *}$ \\ 1. Institute for Industrial, Radiophysical and Environmental Safety, Universitat Politècnica de \\ València, Camino de Vera s/n, 46022 - Valencia, Spain \\ 2. Research Centre in Mechanical Engineering, Universitat Politècnica de València, Camino de \\ Vera s/n, 46022 - Valencia, Spain \\ 3. Tribology and Interfacial Chemistry Group, École Polytechnique Fédérale de Lausanne, \\ Route Cantonale, 1015 Lausanne, Switzerland

\section{* Corresponding author: anigmu@iqn.upv.es}

\begin{abstract}
The tribo-electrochemical behavior of AISI $316 \mathrm{~L}$ has been investigated under tribocorrosion conditions in a $3 \% \mathrm{NaCl}$ solution and the material damage evolution with time has been analyzed. A numerical contact model based on a Boundary Element Method (BEM) has been developed in order to determine the contact pressure distribution and to quantify the worn material as a function of time. The time dependence of the tribological behavior of the material has been described. At the initial state, the high contact pressures generate a material flow causing an increase in the worn area. After around 300 cycles, the Archard wear model linearly describes the wear evolution with time. The proposed model describes the evolution with time of the wear profiles of the tested material and takes into account the plastic behavior of the material during the first cycles.
\end{abstract}

Keywords: tribocorrosion; austenitic stainless steel; ball-on-disc; numerical modelling; wear quantification 


\section{List of symbols}

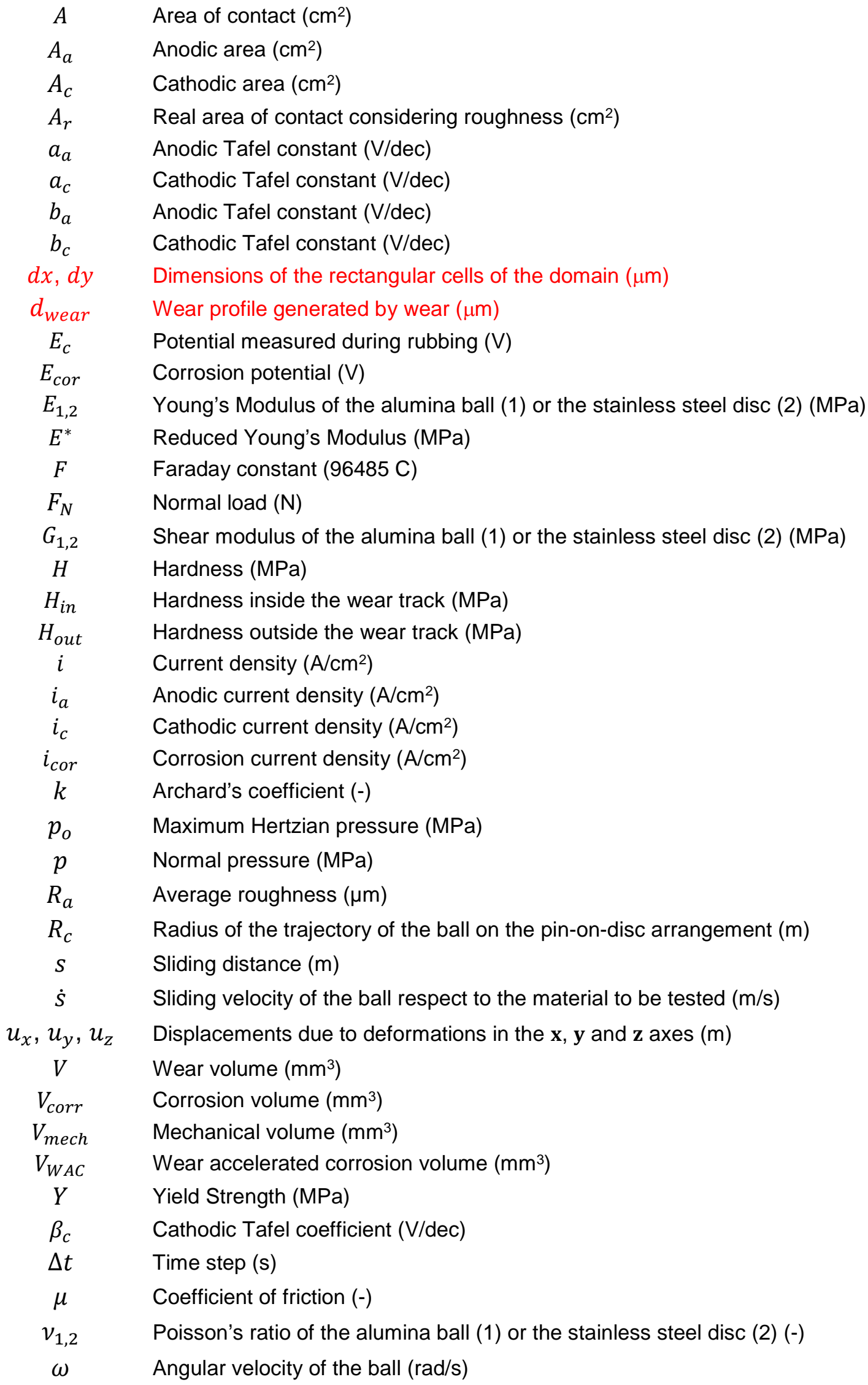




\section{Introduction}

Tribocorrosion is defined as "solid surface alteration that involves the joint action of relatively moving mechanical contact with chemical reaction in which the result may be different in effect than either process acting separately" [1]. From this definition, three different mechanisms can be identified in a tribocorrosion system [2][3]: corrosion, that occurs in the nonrubbed area, on the whole metal surface exposed to the corrosive fluids; wear accelerated corrosion (WAC) which takes place on the worn area where the passive film has been mechanically removed and the underlying metal suffers an increase in corrosion rate and mechanical wear, that occurs in the contact area.

The tribocorrosion phenomenon is therefore a complex multidisciplinary system which has been analytically modeled in the last years [4][5]. It is also a dynamic system which evolution with time may determine the final material damage. When a tribological contact is carried out by a hard counterpart on a flat surface passive material, the softer metal is plastically deformed under specific mechanical conditions due to the contact between the asperities [6]. If the contact is immersed in a corrosive environment, wear degradation will take place by means of two mechanisms: (1) mechanical detachment of contacting asperities, leading to mechanical wear which can be described by the Archard's law [7], and (2) the WAC which occurs due to the plastic deformation of these asperities leading to the release of the metallic ions and the exposure of the bulk metal to the environment [8]. This cyclic process is time dependent as surface properties (topography, roughness or chemical composition) changes with time, thus the contact pressure distribution also changes as tribocorrosion evolves.

The contact stress and strain distribution can be determined by means of continuum mechanics. Numerical models such as Finite Element (FEM) or Boundary Element (BEM) methods combined with specific wear models (i.e. Archard's) allows for describing the wear evolution with time. Several authors have already used FEM for simulating pin-on-disk wear problems in tribometers [9][10][11]. However, when long simulations are needed to take into account the 
profile evolution of non-smooth surfaces, BEMs offer computational advantages with respect to FEMs due to its associated computational costs [12][13]. Sfantos et al. [14] [15] used BEMs in order to model the wear in metal-polymer hip joints, carrying out wear predictions of the head-socket pairs after long operating times. However, those models did not take into account the triboelectrochemical conditions found in tribocorrosion systems, neither the plastic behaviour of the materials at high contact pressures (i.e. at the beginning of the tribocorrosion tests).

The main objective of this study is to describe the dynamic nature of a tribocorrosion system through continuum mechanics approach allowing for determining the contact stress and deformations. A numerical model is proposed and experimentally validated by the measurement of wear after different sliding times in a tribocorrosion situation. To do that, triboelectrochemical techniques have been used.

This manuscript is structured as follows. In a first section the experimental set up attending to the electrochemical measurements and tribocorrosion tests are presented, as well as the characterization of the worn surfaces. In a second section, a numerical model that accounts for sliding contact and wear in tribocorrosion systems is proposed. The following section summarizes the experimental and numerical results. Finally, the discussion and the conclusions are exposed.

\section{Experimental}

\subsection{Material and sample preparation}

An austenitic stainless steel, AISI 316L, was provided by Outokumpu Stainless BA in form of bars of $22 \mathrm{~mm}$ of diameter. These bars were cut in disks of $5 \mathrm{~mm}$ thick by means of a linear precision saw IsoMet 4000 from Buehler equipped with a diamond wafering blade disk at a cutting speed of $2.5 \mathrm{~mm} / \mathrm{min}$. The chemical composition is presented in Table 1. 
Table 1. Chemical composition of the AISI 316L (wt. \%).

\begin{tabular}{cccccccc}
\hline $\mathrm{C}$ & $\mathrm{Ti}$ & $\mathrm{V}$ & $\mathrm{Cr}$ & $\mathrm{Ni}$ & $\mathrm{Mo}$ & $\mathrm{Fe}$ & Others \\
\hline AISI 316L & 0.02 & 0.003 & -16.8 & 10.6 & 2.6 & Bal. & $\begin{array}{c}0.041 \mathrm{~N}, 0.48 \mathrm{Si}, 0.027 \mathrm{P}, 0.001 \mathrm{~S}, \\
1.65 \mathrm{Mn}, 0.36 \mathrm{Cu}, 0.001 \mathrm{Ce}\end{array}$ \\
\hline
\end{tabular}

Before any test, samples were wet-ground with silicon carbide and further polished with $1 \mu \mathrm{m}$ diamond suspension up to a mirror like finishing $\left(R_{a} \approx 0.1 \mu \mathrm{m}\right)$. Then, the specimens were cleaned with acetone and ethanol in an ultrasonic bath during $10 \mathrm{~min}$. The microstructure and the mechanical properties of the material are extracted from previous studies [16][17], in which the initial hardness, the Young's modulus of the material and the Poisson's ratio are $H=2473 \pm 110 \mathrm{MPa}, E_{2}=205 \pm 6 \mathrm{MPa}$ and $v_{2}=0.28$, respectively. The Vickers hardness of the studied stainless steels was measured by means of a microdurometer Duramin of Struers applying $1 \mathrm{Kg}$ during $30 \mathrm{~s}$. The elastic modulus was obtained using an ultrasonic equipment Karl Deutsch - Digital Ecograph and the yield strength data was provided by the manufacturer, which has been obtained following the standard ASTM A514 [17] at the offset yield point of $0.2 \%$. Microstructure of the austenitic one was revealed by immersing the samples in Glyceregia for $1 \mathrm{~min}(15 \mathrm{ml} \mathrm{HCl}, 10 \mathrm{ml}$ glycerol and $5 \mathrm{ml} \mathrm{HNO}$ ) and they were examined using optical and scanning electron microscopy SEM JEOL 6480 LV.

\subsection{Electrochemical measurements}

Electrochemical and tribocorrosion tests were conducted in a naturally aerated $3 \% \mathrm{NaCl}$ solution $(\mathrm{pH}=6)$ at room temperature using a three-electrode electrochemical cell connected to a Solartron 1286 potentiostat. A platinum wire was used as counter electrode and a $\mathrm{Ag} / \mathrm{AgCl}(3 \mathrm{M} \mathrm{KCl})$ as reference electrode, which standard potential is $205 \mathrm{mV}$ with respect to the Standard Hydrogen Electrode (SHE) at $25{ }^{\circ} \mathrm{C}$. All potentials are given with respect to this reference electrode. The sample area exposed to the electrolyte was $2.56 \mathrm{~cm}^{2}$.

Samples were kept at a cathodic potential of $-1.1 \mathrm{~V}$ during $300 \mathrm{~s}$ and then they were left at Open Circuit Potential (OCP) during $1800 \mathrm{~s}$. Afterwards, 
cathodic polarization curves were performed by scanning the potential from OCP to $-1.1 \mathrm{~V}$ at a scan rate of $1 \mathrm{mV} / \mathrm{s}$.

\subsection{Tribocorrosion tests}

Tribocorrosion experiments were carried out on a ball-on-disc tribometer (MicroTest Model MT/60/NI/CORR), which configuration was explained elsewhere [18][17]. The electrochemical cell detailed in the previous section was integrated into the tribometer in order to monitor the electrochemical response.

The AISI 316L was rubbed against an alumina $\left(\mathrm{Al}_{2} \mathrm{O}_{3}\right)$ ball $3 \mathrm{~mm}$ radius at an angular velocity $\omega=60 \mathrm{rpm}$ (which corresponds to a sliding velocity of $18.8 \mathrm{~mm} / \mathrm{s}$ ) and applying a normal load of $F_{N}=5 \mathrm{~N}$. Considering the mechanical properties of the alumina ball $\left(E_{1}=300 \mathrm{MPa}\right.$ and $\left.v_{1}=0.21\right)$, this gives a maximum initial Hertzian contact pressure of $p_{o}=1221 \mathrm{MPa}$.

The rubbing time was varied for each test: $10 \mathrm{~s}, 60 \mathrm{~s}, 300 \mathrm{~s}, 1800 \mathrm{~s}$ and $3600 \mathrm{~s}$.

The tribocorrosion tests were carried out according to the following steps:

- $\quad$ Cathodic polarization by applying a potential of $-1.1 \mathrm{~V}$ for $300 \mathrm{~s}$.

- Open circuit potential (OCP) for $3600 \mathrm{~s}$.

- Sliding during the "rubbing time" while the OCP is maintained.

- $\quad$ Sliding is stopped while the OCP is maintained for $1200 \mathrm{~s}$.

All tests were repeated twice to check for reproducibility.

\subsection{Wear characterisation}

Wear volumes were quantified using an Olympus LEXT OLS3000 confocal microscope, which allows measuring the profiles across the wear track in each sample. The wear track volumes were determined by multiplying the area of the profiles by the length of the wear track. Thus, the values of the Archard's coefficient $k$ were obtained by dividing the total wear volume $V$ times the hardness of the softer material $H$, by the sliding distance $s$ and the normal force $F_{N}$ : 


$$
k=\frac{V H}{F_{N} S}
$$

In order to analyse the wear morphology, wear tracks were observed by an optical and a high resolution scanning electron microscope (SEM Zeiss Auriga Compact).

Microhardness outside and inside the wear track after the tribocorrosion tests was measured by means of a microdurometer Duramin of Struers applying $1 \mathrm{~kg}$ during $30 \mathrm{~s}$ with a Vickers indenter (HV).

\section{Numerical contact and wear model}

A numerical wear model that accounts for mechanical and chemical degradation mechanisms will be presented and applied to the previous tribocorrosion results. The model is developed to reproduce a pin-on-disc test as shown in Figure 1, where a hard ball is loaded and slides on a disc made of the material to be tested. At the beginning of the test, the disc has an initial flat surface, however, as the ball slides on the metallic surface a wear track is formed which profile tends to be a circular sector with the radius of the ball.

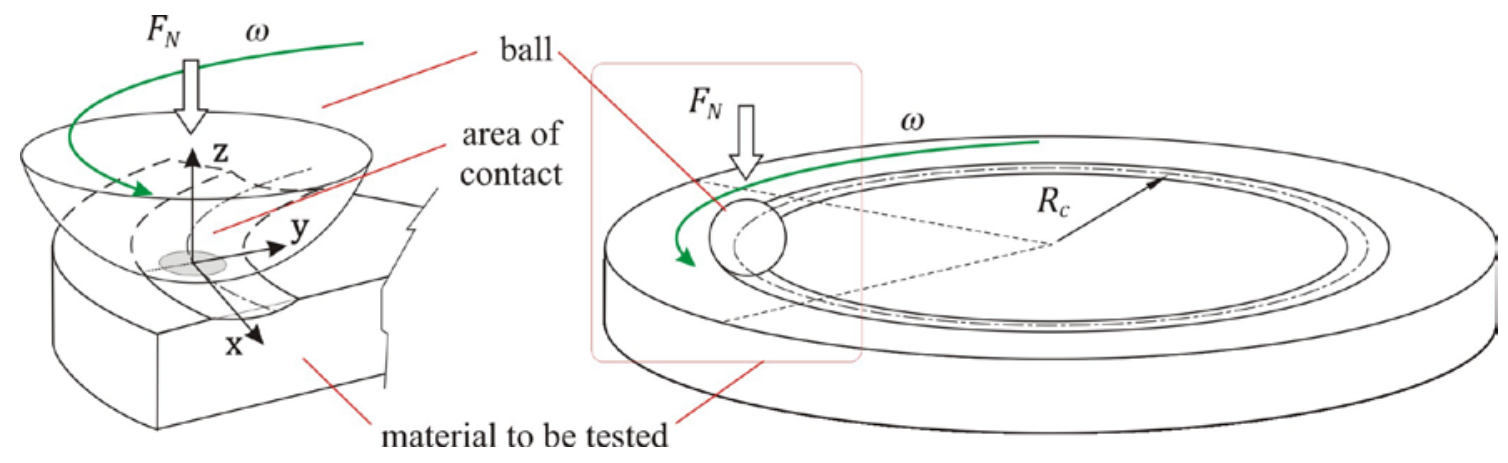

Figure 1. Diagram of a pin-on-disc arrangement.

\subsection{Contact model}

The contact model follows a Boundary Element Model (BEM) for obtaining the normal pressure distribution $p(x, y)$ that leads to a certain normal surface deformation $u_{z}(x, y)$, where $x$ and $y$ are the coordinates of a generic point in the plane of contact (Figure 1). The model assumes the absence of adhesion. 
The contact is made between body 1 (the $\mathrm{Al}_{2} \mathrm{O}_{3}$ ball) and body 2 (the AISI 316L disc) where the initial geometries of the bodies are defined by the functions $z_{1}=\mathrm{f}_{1}(x, y)$ and $z_{2}=\mathrm{f}_{2}(x, y)$, respectively. Then $d(x, y)$ is the separation, or distance between underformed surfaces, calculated as $d(x, y)=z_{1}+z_{2}$.

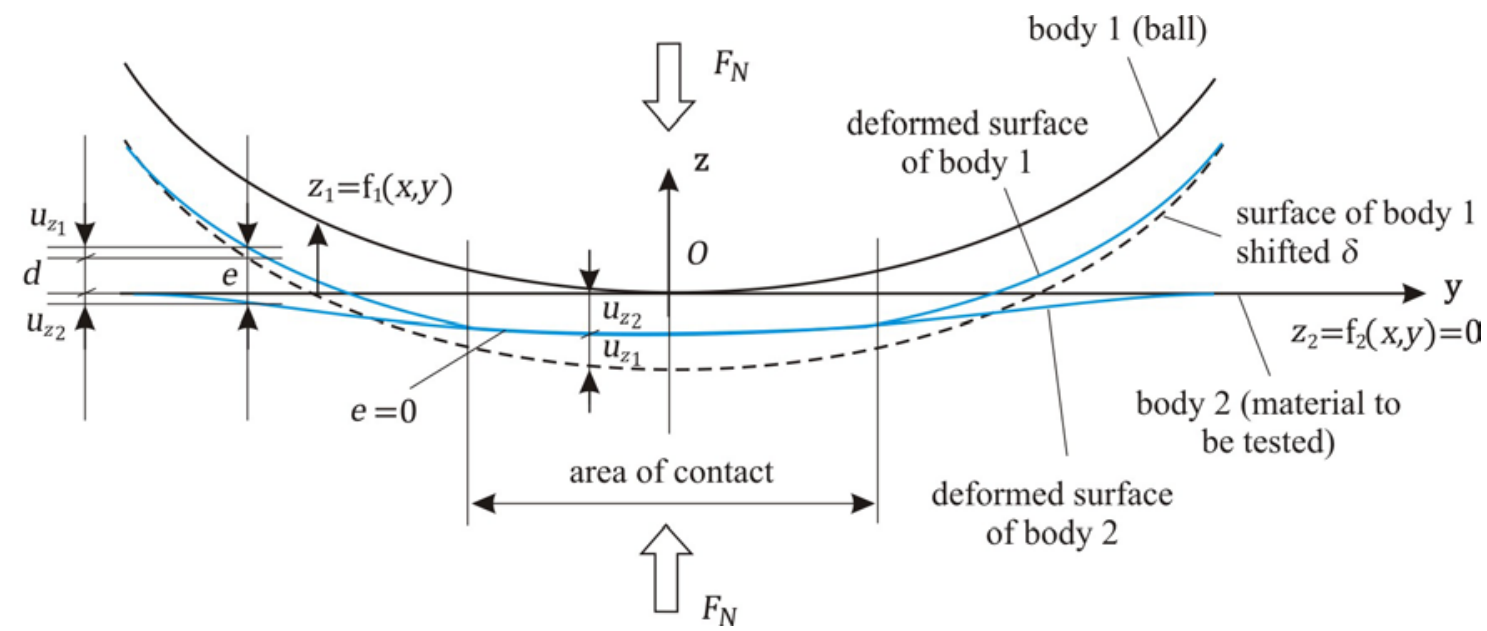

Figure 2. Modelling of the contact between the two surfaces. Adapted from [19].

When a normal force $F_{N}$ is applied, the surfaces of the bodies are elastically deformed, being $u_{z}(x, y)=u_{z_{1}}+u_{z_{2}}$ the normal displacements due to the deformation of the bodies. As a consequence, body 1 indents the body $2 \mathrm{a}$ distance $\delta$, thus generating an area of contact (Figure 2).

The gap between the two bodies, $e(x, y)$, is calculated as [19]:

$$
e(x, y)=d(x, y)-\delta+u_{z}(x, y)
$$

where this magnitude is always positive or zero. Within the area of contact the gap is null $(e(x, y)=0)$, so the surface deformation is calculated as

$$
u_{z}(x, y)=-(d(x, y)-\delta)
$$

In the modelled situation, the contacting surfaces are under sliding conditions where $\mathbf{x}$-axis indicates the direction of motion. Due to the symmetry of the contact problem, the lateral force $F_{y}$ is neglected. The longitudinal force $F_{x}$ is limited by the coefficient of friction, so that $F_{x}=\mu F_{N}$. Translating these conditions from the global to local stress relationships, one obtains: 


$$
\begin{aligned}
& q_{x}=\mu p \\
& q_{y}=0
\end{aligned}
$$

where $q_{x}$ is the tangential stress in the longitudinal direction ( $\mathbf{x}$ axis) and $q_{y}$ is the tangential stress in the lateral direction ( $y$ axis).

An elastic model is used to relate the normal surface deformation $u_{z}(x, y)$ with the contact pressures. The contact model considers semi-infinite solids of nominally smooth surfaces and an initial ball on flat contact. The surface deformations $\left\{\begin{array}{lll}u_{x} & u_{y} & u_{z}\end{array}\right\}^{T}$ at any point $I \equiv\left\{\begin{array}{lll}x & y & 0\end{array}\right\}^{T}$ due to normal and tangential pressures $\left\{q_{x} 0 p\right\}^{T}$ acting on another surface point $J \equiv\{\xi \eta 0\}^{T}$ can be calculated using the half-space approximation given by the Boussinesq-Cerruti relations [19][20]:

$$
u_{z}(x, y)=\frac{1}{\pi E^{*}} \iint_{A} \frac{p(\xi, \eta)}{r} d \xi d \eta+\frac{1}{\pi G^{*}} \iint_{A} \frac{q_{x}(\xi, \eta)(x-\xi)}{r^{2}} d \xi d \eta
$$

where $E^{*}$ and $G^{*}$ are the reduced Young's and shear moduli of the materials calculated as

$$
\begin{gathered}
\frac{1}{E^{*}}=\frac{1-v_{1}^{2}}{E_{1}}+\frac{1-v_{2}^{2}}{E_{2}} \\
\frac{1}{G^{*}}=\frac{1}{G_{1}}+\frac{1}{G_{2}}
\end{gathered}
$$

with $v_{1}, v_{2}, G_{1}$ and $G_{2}$ being the Poisson's ratio and the shear moduli of both materials, respectively. And $r=\sqrt{(x-\xi)^{2}+(y-\eta)^{2}}$ is the distance between the surface points.

In order to solve the double integrals, the computational area is divided in a regular rectangular mesh of dimensions $2 a \times 2 b$, where the contact pressures are supposed to be constant in each element. The normal surface deformations $u_{z}$ at any point $I \equiv\left\{\begin{array}{lll}x & y & 0\end{array}\right\}^{T}$ due to constant normal and tangential pressures $\left\{\begin{array}{lll}q_{x} & 0 & p\end{array}\right\}^{T}$ acting on another element centered in $J \equiv\left\{\begin{array}{lll}\xi & 0\end{array}\right\}^{T}$ can be calculated as previously proposed by Björklund and Andersson [20]:

$$
u_{z}^{I}=\left[\begin{array}{ll}
C_{z, x}^{I, J} & C_{z, z}^{I, J}
\end{array}\right]\left\{\begin{array}{c}
\mu p \\
p
\end{array}\right\}^{J}=\frac{-\frac{1}{2} \Delta v g_{x, z} \mu+\left(1-v^{*}\right)\left(g_{x, x}^{A}+g_{x, x}^{B}\right)}{2 \pi G^{*}} p^{J}
$$


where

$$
\begin{gathered}
v^{*}=\frac{v_{1} G_{2}+v_{2} G_{1}}{G_{1}+G_{2}} \\
\Delta v=\frac{\left(1-2 v_{1}\right) G_{2}-\left(1-2 v_{2}\right) G_{1}}{G_{1}+G_{2}}
\end{gathered}
$$

and $g_{i, j}$ are functions of $x, y, a$ and $b$ and they are double integrals solved in [20] (the expressions of these functions are given in Appendix $A$ ), which allows obtaining the influence coefficients $C^{I, J}$.

$$
\begin{gathered}
g_{x, z}=\int_{-b}^{b} \int_{-a}^{a} \frac{(x-\xi) d \xi d \eta}{r^{2}} \\
g_{x, x}^{A}+g_{x, x}^{B}=\int_{-b}^{b} \int_{-a}^{a} \frac{d \xi d \eta}{r}
\end{gathered}
$$

Considering the computational area, the normal surface deformation can be calculated from:

$$
u_{z}^{I}=\sum_{J}\left(C_{z, x}^{I, J} \mu+C_{z, Z}^{I, J}\right) p_{J}
$$

Therefore, the contact pressure is obtained by solving equation (10), where the normal surface deformation of each element of the mesh can be calculated assuming that the element is in contact (equation (3)). It must be considered that the calculated pressure must be positive (otherwise, the corresponding element does not belong to the area of contact) and that the integral of the pressures yields the normal force. These constraints are expressed through the following equations:

$$
\begin{aligned}
& p^{J}>0 \\
& F_{N}=\sum_{J} p^{J} d x d y
\end{aligned}
$$

The proposed model is modified in order to deal with the plasticity of softer materials in a simplistic way while the strain-stress relationship in the materials remains elastic. Therefore, a simple elastic-perfectly-plastic (EPP) model for the AISI $316 \mathrm{~L}$ is used and the maximum normal pressure before the material plastically deforms is assumed to be: 


$$
p \leq Y
$$

being $Y$ the yield strength, which can be roughly estimated from the measured hardness $H$ of the softer material as $Y=H / 2.8$ [19].

The solution of the system of equations (10), (11) and (12) is obtained by solving a quadratic problem with bound constraints using the Bound-Constraint Conjugate Gradient (BCCG), a method proposed by Vollebregt et al. [21]. This method combines the Conjugate Gradient (CG) method with an active strategy that truncates variables crossing the bounds, i.e. $0 \leq p(x, y) \leq Y$. The most demanding computational effort comes from the operations of equation (10). These operations are optimised by using the discrete convolution - fast Fourier transform (DC-FFT) technique proposed by Liu [22].

\subsection{Wear quantification}

The wear model will allow obtaining the evolution of wear in a tribological test given the contact geometry, the mechanical properties of the materials and the contact pressure distribution. It considers that the wear profile can be formed by two mechanisms: (1) by a fast groove generation during the initial cycles due to bare metal yielding when some contact pressures reach the yield strength of the material and (2) by material removal due to plastic wear of the asperities in contact between the bodies when the contact pressures decrease below $Y$, thus leading to an elastic behavior of the material.

During the initial cycles, some contact pressures reach the yield strength of the material and the material under the ball is pushed away. Under this condition, the wear profile $d_{\text {wear }}$ generated due to the material yielding is calculated subtracting, in the contact area, the depth of the profile of the ball indentation $\delta-h(x, y)$ to the deformation $u_{z}(x, y)$ related to the contact pressure distribution (limited to $0<p(x, y) \leq Y$ ),

$$
d_{\text {wear }}(x, y)=(\delta-d(x, y))-u_{z}(x, y)
$$

The wear depth profile (in the $\mathbf{y}$ direction) when the ball passes through a reference plane (in the $\mathbf{x}$ direction) every cycle is calculated as the maximum of the wear profile $d_{\text {wear }}$ due to yielding for each $\mathbf{y}$ coordinate. 
After the initial cycles, when all the contact pressures are below the yield strength $(0<p(x, y)<Y)$, the wear model used is the Archard's law, which in its global form is expressed as:

$$
V=k \frac{F_{N} S}{H}
$$

where $V$ is the wear volume, $k$ is the Archard's coefficient, $F_{N}$ is the normal load, $H$ is the hardness of the softer material and $s$ is the sliding distance between the solids in contact. Equation (14) can be expressed in a local form dividing it by the area $d x \cdot d y$ of a rectangular cell of the computational area (Figure 3), which gives

$$
d_{\text {wear }}(x, y)=k \frac{p(x, y) s}{H}
$$

where $d_{\text {wear }}(x, y)$ is the depth of the removed material in the element (or wear depth) and $p(x, y)$ is the pressure supported by the cell. The sliding distance $s$ is calculated as the product of the sliding velocity $\dot{s}$ and the considered time step $\Delta t$.

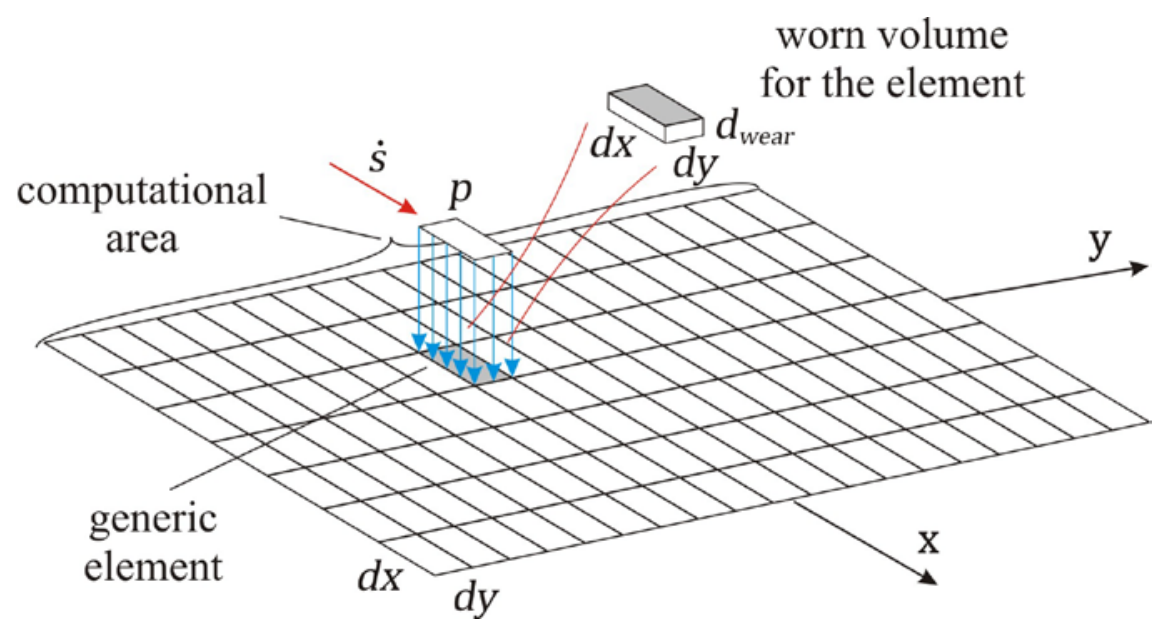

Figure 3. Calculation of the wear depth for an element of the computational area.

In order to calculate the wear on the profile $d(y)$, the wear depth values $d_{\text {wear }}(x, y)$ are then summed over the longitudinal direction $\mathbf{x}$ :

$$
d(y)=\int d_{\text {wear }}(x, y) d x
$$

This wear on the profile is transferred to the distance between nondeformed surfaces (profile updating). Thus, equation (3) should be written as 


$$
u_{z}(x, y)=-(d(x, y)-\delta-d(y))
$$

Figure 4 shows the flowchart of the procedure used to calculate the profile evolution with time. Given the geometry of the initial surfaces, the material properties and behavior, the contact problem is solved for every cycle (every pass of the ball in a wear track position) considering a quasi-static problem. The pressure distribution obtained after each cycle is then used to calculate the wear depth and the worn surface is accordingly updated. The yield strength used to limit the contact pressures (equation (12)) and the hardness of the softer material used to calculate wear by Archard's law (equation (15)) are taken from the experimental measurements and updated for every cycle. The simulation is run until the final condition (to reach a certain number of cycles) is fulfilled.

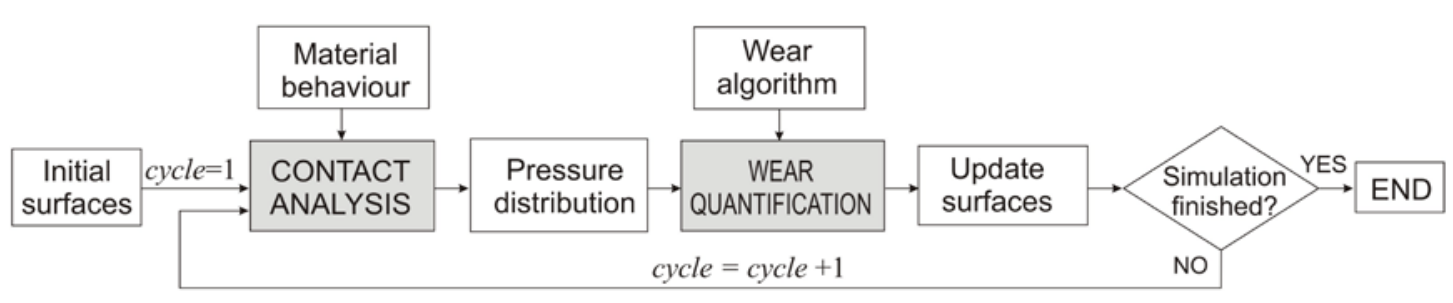

Figure 4. Flowchart of the proposed procedure.

\section{Experimental and numerical results}

\subsection{Electrochemical measurements}

Figure 5 shows the cathodic polarization curves of the AISI 316L alloy in the $3 \% \mathrm{NaCl}$ solution after $1 \mathrm{~h}$ of OCP, which value was $-0.10 \mathrm{~V}$. Tafel domain is observed below potentials of $-0.15 \mathrm{~V}$, in which the absolute value of the current density linearly increases with the applied potential. Table 2 summarizes the electrochemical parameters extracted from the polarization curves, as well as the Tafel coefficients obtained from the slope of the linear domain of the potentiodynamic curve (Tafel domain). 


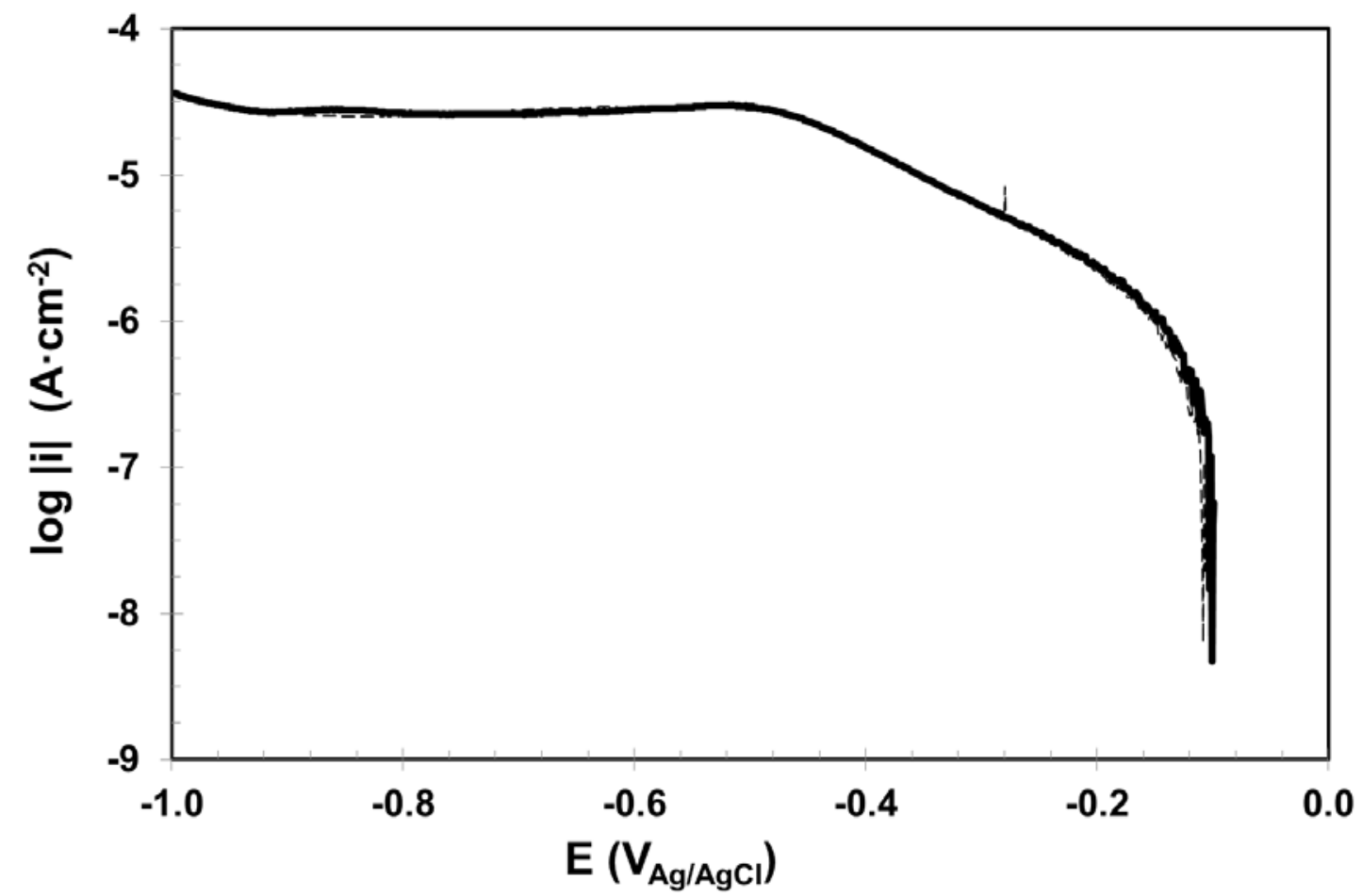

Figure 5. Cathodic polarization curve of the AISI 316L (and its repetition in dashed points) in a $3 \% \mathrm{NaCl}$ solution at room temperature.

Table 2. Electrochemical parameters and Tafel constants extracted from the linear regression of the cathodic polarization curves of the AISI 316L.

\begin{tabular}{cccc}
\hline$E_{\text {corr }}(V)$ & $i_{\text {corr }}\left(\mu \mathrm{A} / \mathrm{cm}^{2}\right)$ & $a_{c}(\mathrm{~V} / \mathrm{dec})$ & $b_{c}(\mathrm{~V} / \mathrm{dec})$ \\
\hline$-0.10 \pm 0$ & $1.13 \pm 0.06$ & $-3.31 \pm 0.07$ & $0.56 \pm 0.01$ \\
\hline
\end{tabular}

\subsection{Tribocorrosion tests}

The evolution of the potential with time for the different rubbing times $(\mathrm{t}=10 \mathrm{~s}, 60 \mathrm{~s}, 300 \mathrm{~s}, 1800 \mathrm{~s}$ and $3600 \mathrm{~s}$ ) is shown in the Figure 6a and b. Before sliding, the OCP was maintained for $1 \mathrm{~h}$ in order to stabilize the growth of the passive film on the sample. The OCP value abruptly decreases after the initiation of the sliding due to the mechanical detachment of the passive film. A shift of the potential to more anodic values is observed when the sliding is stopped due to the repassivation of the worn area. Other researchers found the same behaviour within their OCP tribocorrosion tests in the AISI 316L [23][24]. 
a

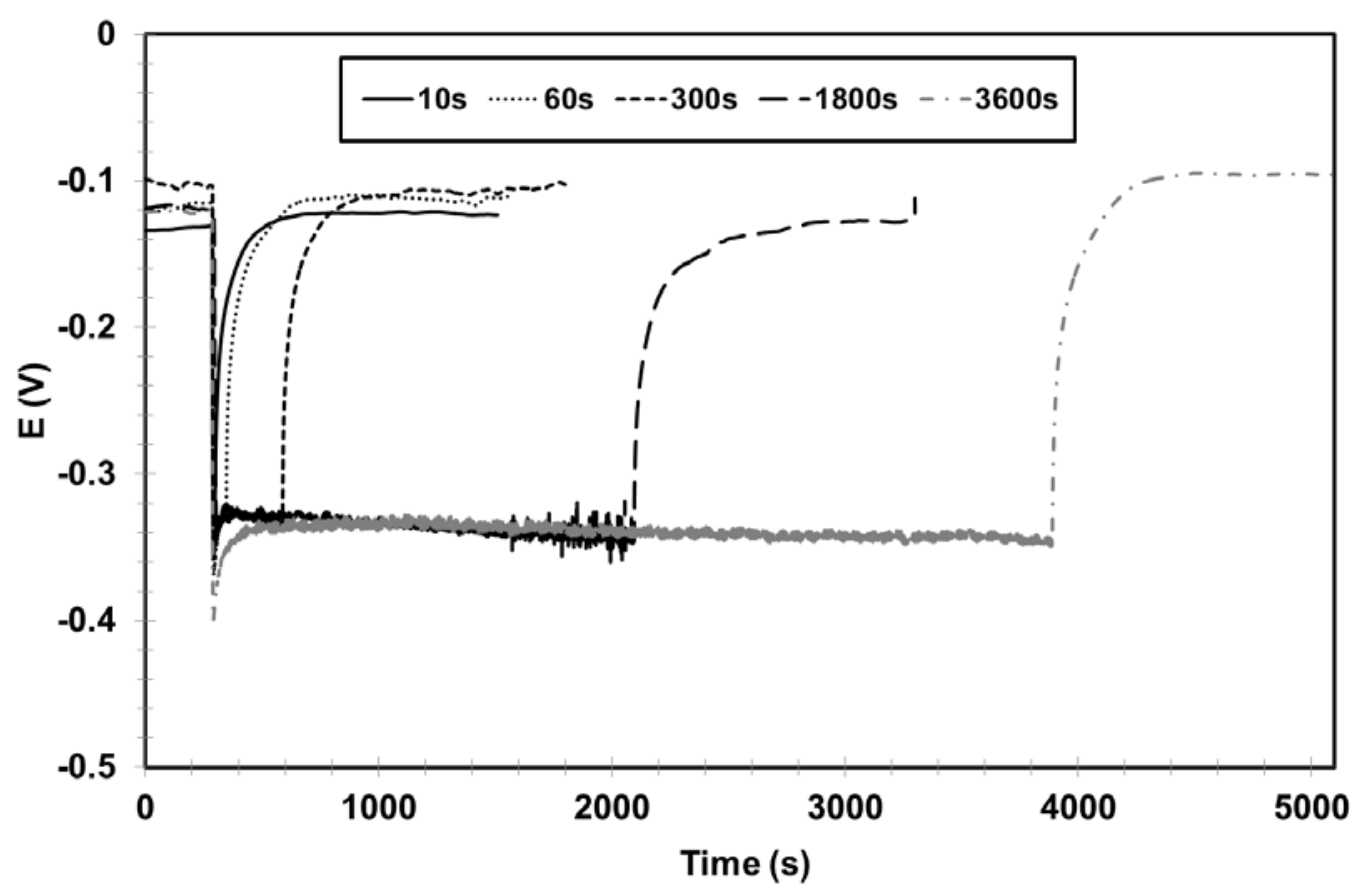

b

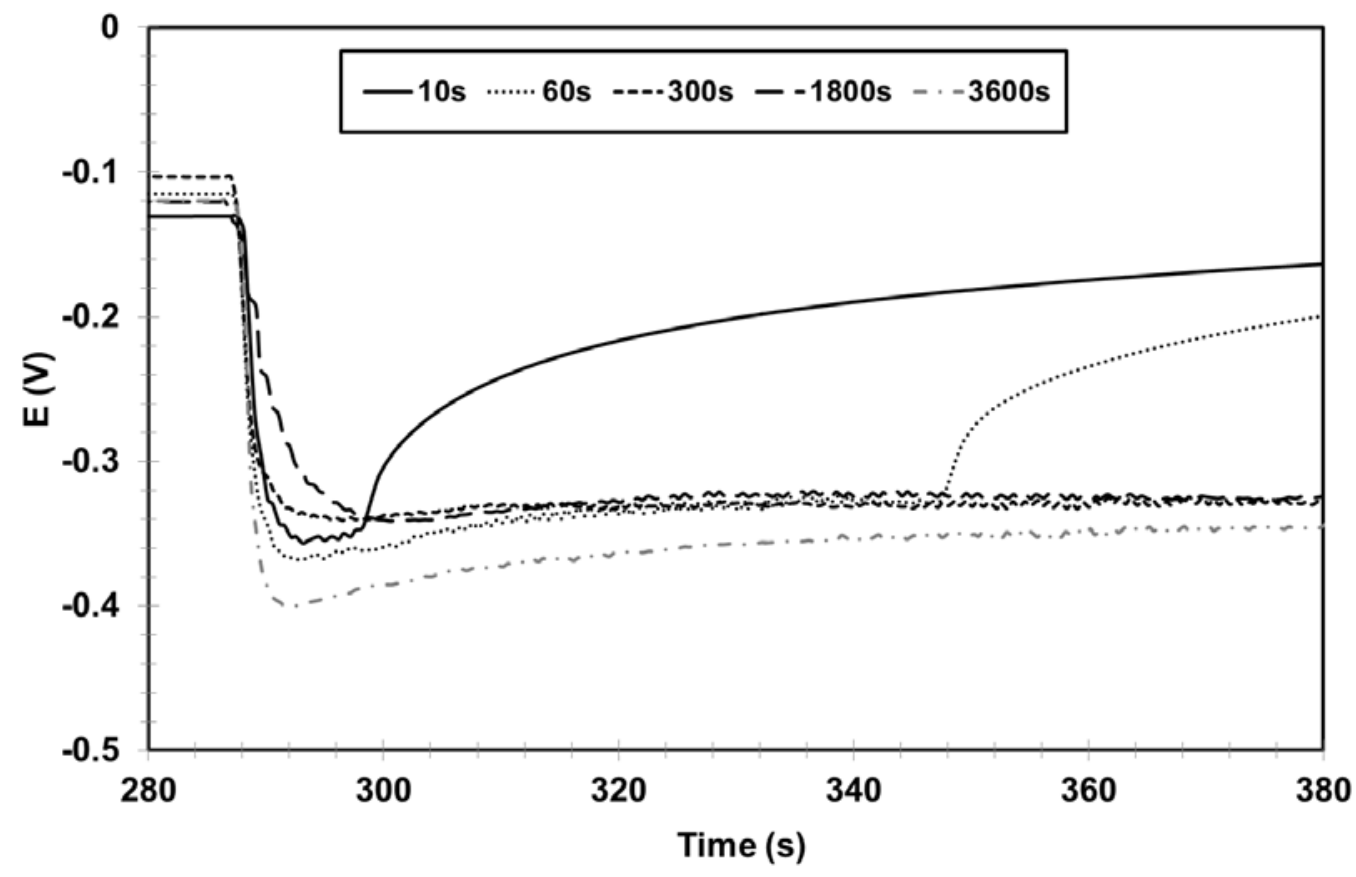

Figure 6. (a) Evolution of the potential of the AISI 316L with time during sliding at OCP in a $3 \%$ $\mathrm{NaCl}$ solution during different rubbing times and (b) its enlargement $\left(F_{N}=5 \mathrm{~N}, \omega=60 \mathrm{rpm}\right)$.

\subsection{Friction, hardness and experimental wear quantification}

Figure $7 a$ and $b$ show the evolution of the coefficient of friction with time in the tribocorrosion tests. The value of the coefficient of friction is practically constant around a value of 0.45 . This value indicates that plastic deformation occurs at the surface [19]. 
a

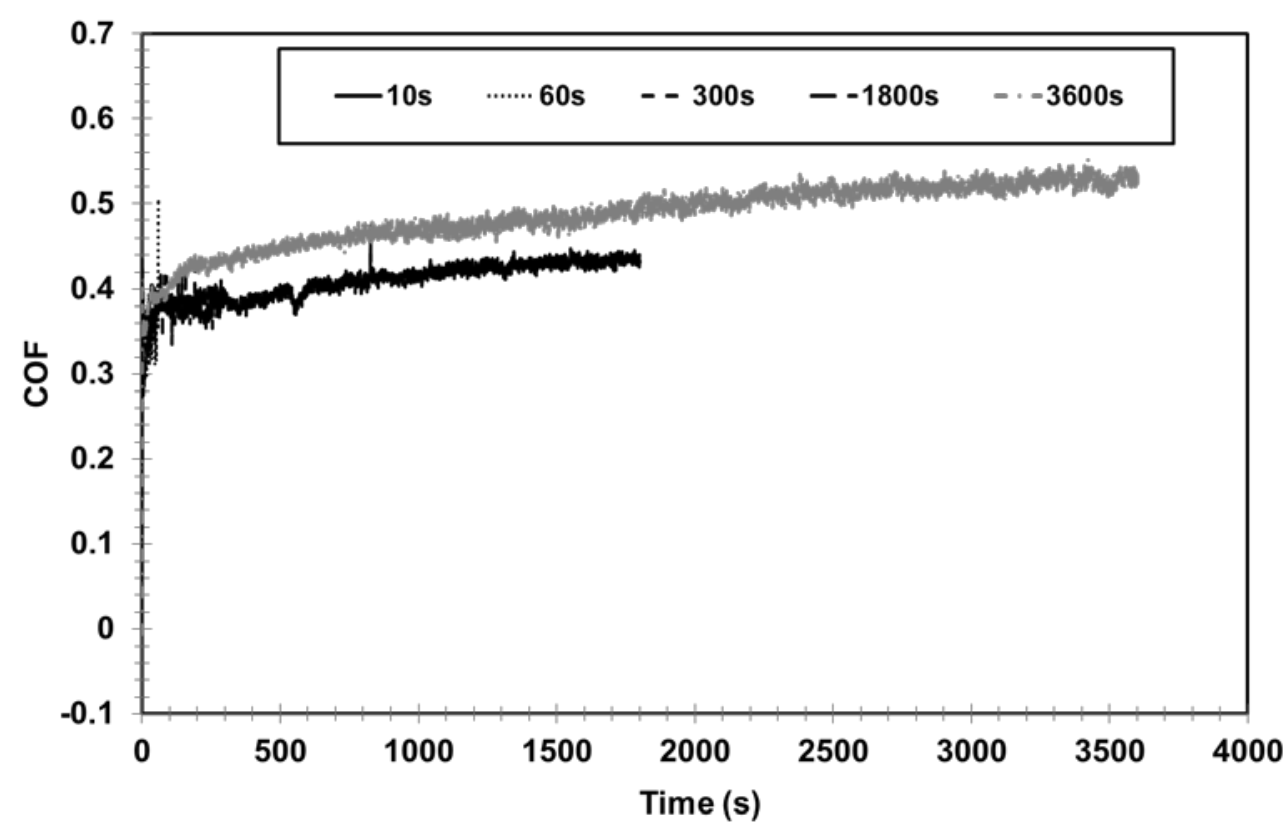

b

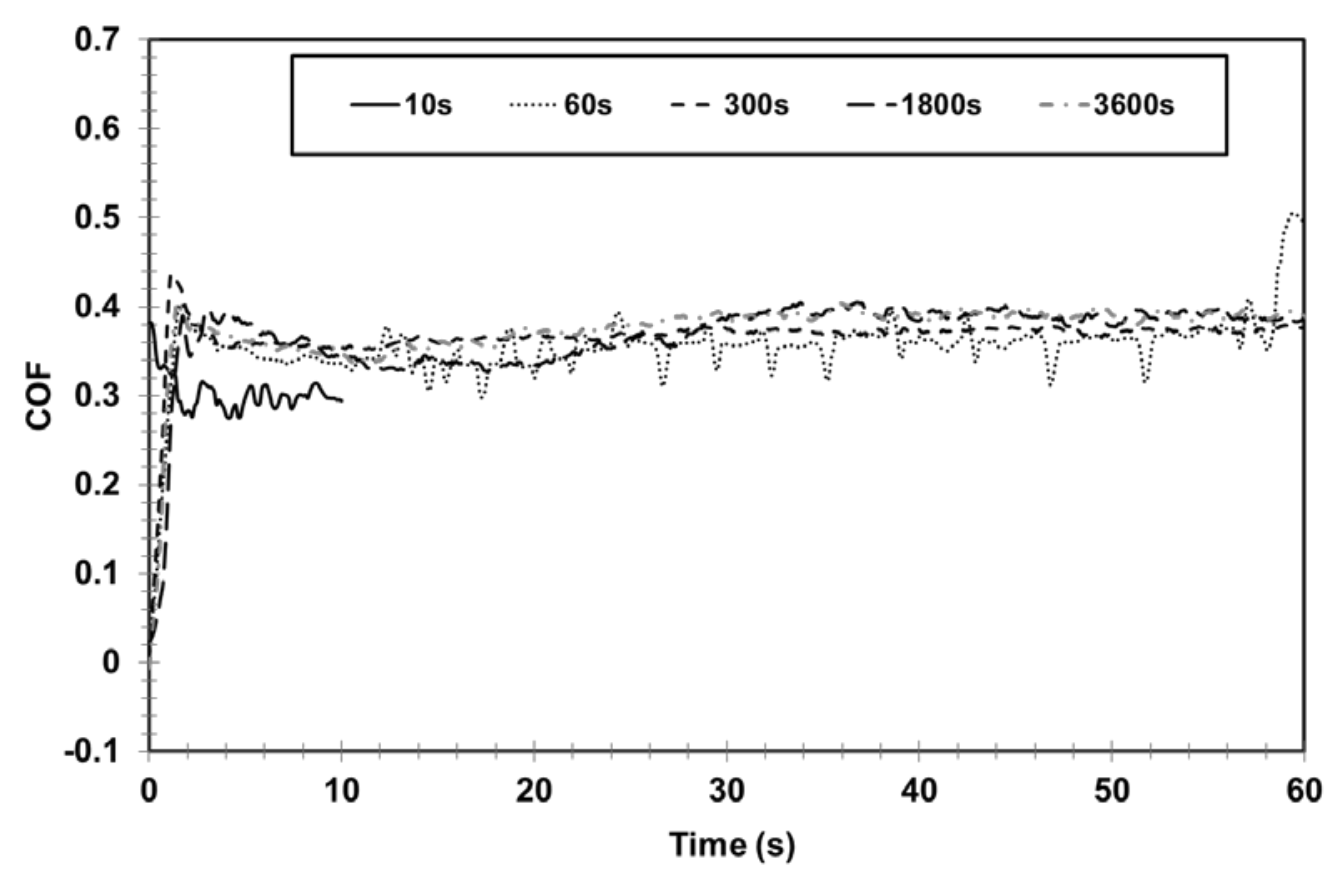

Figure 7. (a) Evolution of the coefficient of friction $(\mu)$ with time in the tribocorrosion tests of AISI316L sliding against an alumina ball and (b) its enlargement $\left(F_{N}=5 \mathrm{~N}, \omega=60 \mathrm{rpm}\right)$.

After the different sliding times of the tribocorrosion tests, the wear loss volume of the AISI 316L wear track was calculated from the wear track profiles obtained by confocal microscopy. Material transfer from the AISI 316L to the counterpart and wear of the alumina ball were not observed. The microhardness values were measured inside the wear track and the ratio between the hardness inside and outside the wear track $\left(H_{\text {in }} / H_{\text {out }}\right)$ were obtained. These values are summarized in Table 3 . An increase of the 
hardness inside the wear track after the tribocorrosion tests is observed due to the work hardening induced by the sliding.

Table 3. Wear volumes $\left(V_{\text {tot }}\right)$ and hardness values outside (bulk metal) and inside the wear track for the different rubbing times $\left(F_{N}=5 N\right)$ and the ratio $H_{\text {in }} / H_{\text {out }}$ at the end of the tribocorrosion tests.

\begin{tabular}{cccc}
\hline Rubbing time (s) & Hardness $(\mathbf{M P a})$ & $\boldsymbol{H}_{\text {in }} / \boldsymbol{H}_{\text {out }}$ & $\boldsymbol{V}_{\text {tot }}\left(\cdot \mathbf{1 0}^{-\mathbf{3}} \mathbf{m m}^{\mathbf{3}}\right)$ \\
\hline Bulk metal & $2473 \pm 110$ & 1.00 & - \\
10 & $2551 \pm 90$ & 1.05 & $0.97 \pm 2.0$ \\
60 & $2727 \pm 90$ & 1.13 & $1.09 \pm 0.1$ \\
300 & $2854 \pm 10$ & 1.18 & $1.18 \pm 0.0$ \\
1800 & $2933 \pm 90$ & 1.21 & $5.33 \pm 0.7$ \\
3600 & $2953 \pm 90$ & 1.22 & $11.72 \pm 0.2$ \\
\hline
\end{tabular}

\subsection{Wear morphology}

SEM micrographs of the wear track after the tribocorrosion tests at different rubbing times are presented in Figure 8. It is possible to observe rougher surface at the beginning of the tests, Figure 8a, and the build up of third bodies. Some delamination occurs, Figure $8 \mathrm{c}$. Surfaces are smoother with the appearance of grooves and less wear debris as rubbing time increases, Figure 8e. 

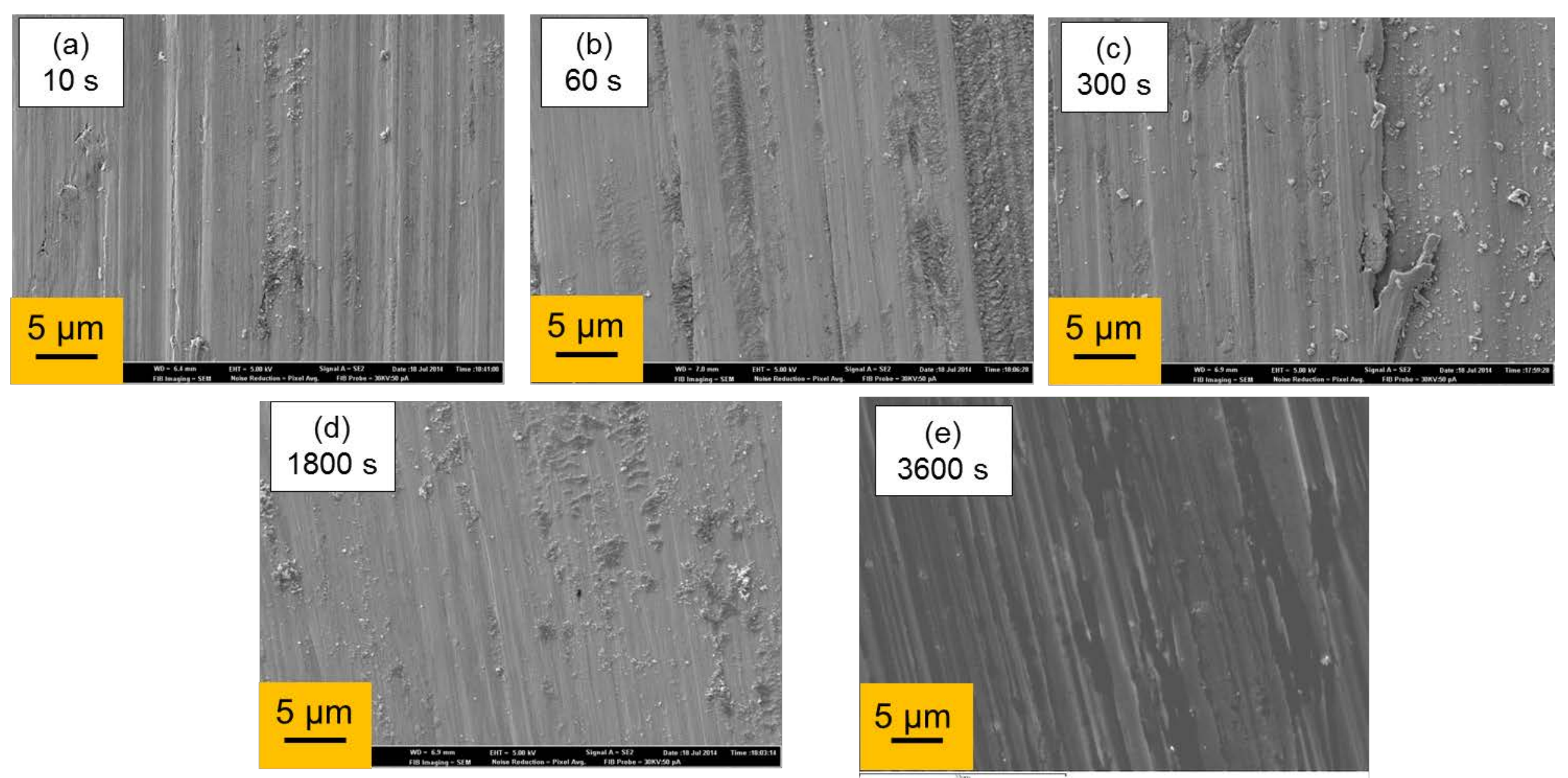

Figure 8. SEM micrographs of the wear track after the different tribocorrosion tests of the AISI $316 \mathrm{~L}$ in a $3 \% \mathrm{NaCl}$ solution at room temperature: (a) 10 s, (b) 60s, (c) 300s, (d) 1800s and (e) 3600s. 


\subsection{Numerical results}

Using the numerical contact and wear model proposed in Section 3, first the local contact pressure distribution is determined for every cycle and then the wear track profile and the wear evolution with time is predicted. The geometrical and mechanical properties of the alumina ball and the AISI 316L reported in Section 2 are used in the initial step for calculating the contact pressures. In the following steps, while maintaining the geometry and mechanical properties of the alumina ball, the surface profile $\left(u_{z_{2}}(x, y)\right)$ of the AISI $316 \mathrm{~L}$ is being updated to account for the wear track profile evolution and the yielding condition for the AISI 316L is obtained from the experimental hardness values measured inside the wear track given in Table $3(Y=H / 2.8)$.

In order to use a smooth variation of the hardness in the numerical wear model, a logarithmic expression is used to fit the experimental evolution of the hardness with time, Figure 9. From this figure it is possible to observe a significant increase in hardness during the initial cycles; however, as the number of cycles $(n)$ growths, the rate of hardness increase is reduced resulting in a quasi-asymptotic trend.

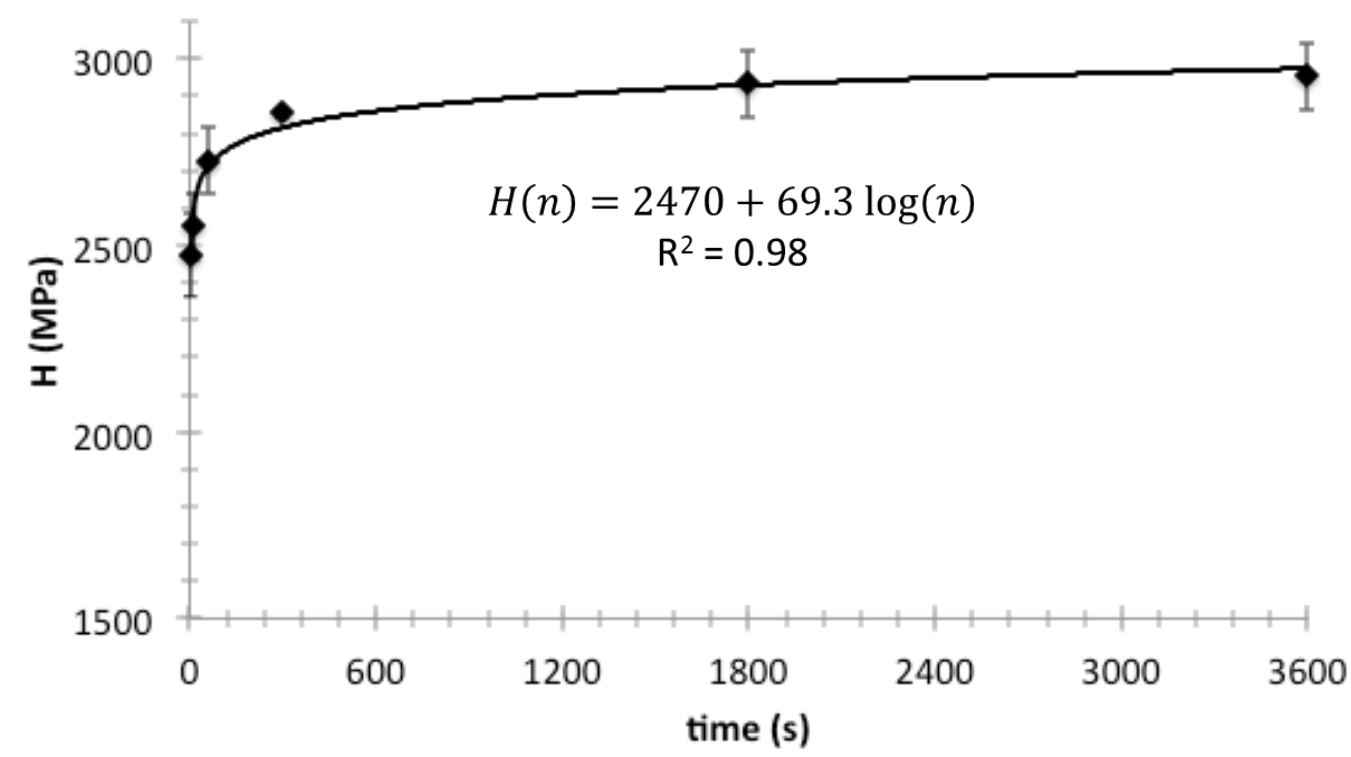

Figure 9. Hardness evolution of the AISI 316L: diamonds - experimental data; line - fitted curve. Where $n$ is the number of cycles 
The dimensions of the computational area are $0.256 \times 0.256 \mathrm{~mm}$ and it is divided in a regular mesh of $256 \times 256$ elements $(1 \times 1 \mu \mathrm{m}$ in size). The direction of relative motion of the ball against the sample follows the positive $\mathbf{x}$ direction and the wear profile is supposed to be the same for all the computational area.

Figure 10 shows the contact pressure distribution when the alumina ball slides against the AISI $316 \mathrm{~L}$ at the initial steps of the simulation and after several cycles. During the initial cycles, the contact pressure inside the contact area (Figure 10.a) reaches the yielding condition (equation 12), increasing the contact area to accommodate the excess of elastic stresses. As the groove of the wear track increases, the shape of the contact area changes from an initial circular or elliptical area to a rectangular one with rounded corners. After those initial cycles (around 10 cycles) all the contact pressures reduce below the yielding condition, as can be seen in Figure 10.b. In this situation the maximum contact pressure is located at the edges of the wear track groove. Along the simulation, the shape of the contact area increases in width (y direction) and reduces in length ( $\mathbf{x}$ direction).

a

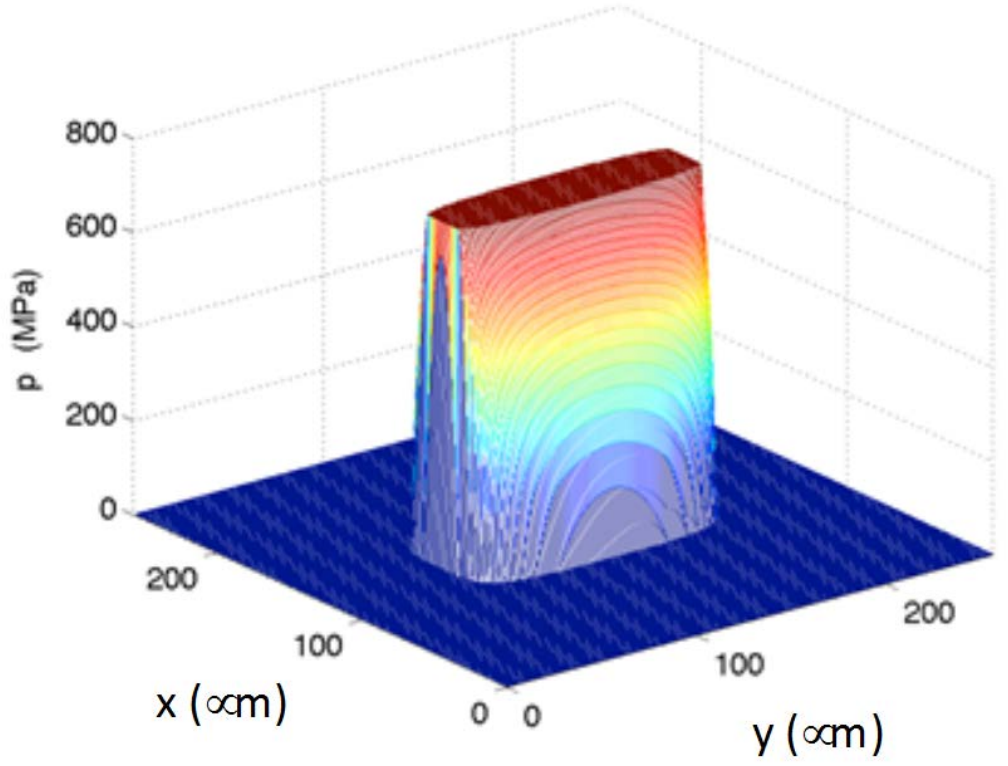




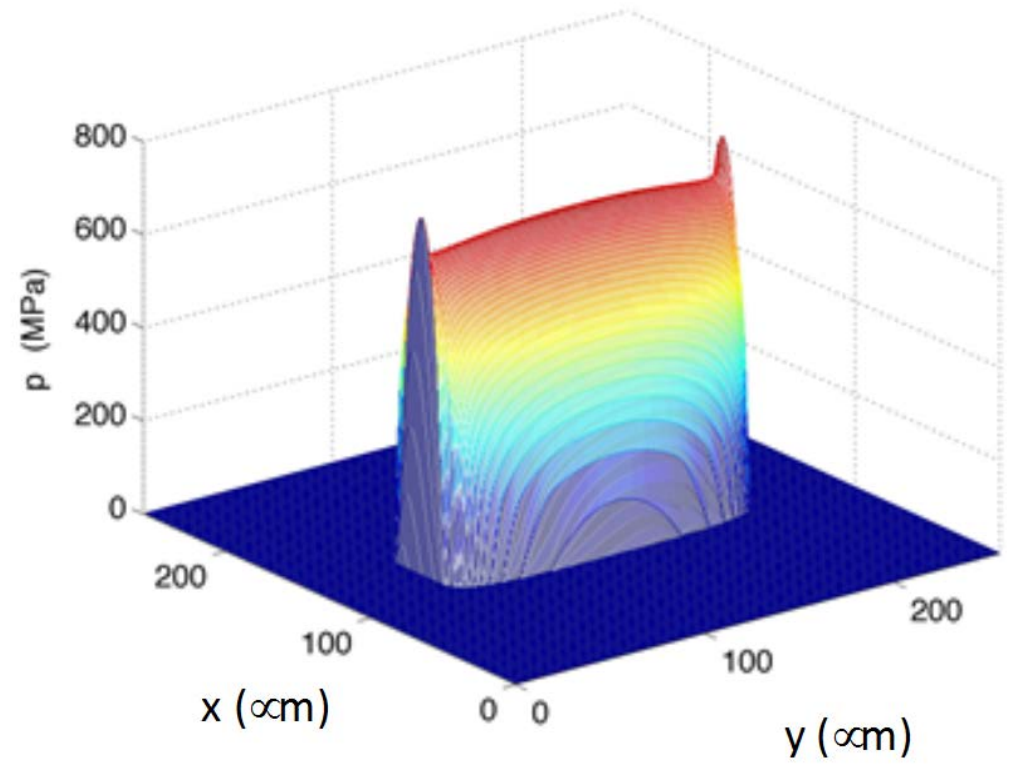

Figure 10. Contact normal pressure distribution: (a) at 6 cycles; (b) at 300 cycles.

Once the contact pressure distribution is obtained for every cycle, the wear track profile is calculated at every cycle with the numerical wear model proposed in Section 3. In addition to the computed pressures, the model makes use of the coefficient of friction $\mu$, the AISI 316L hardness $H$ and the Archard's coefficient $k$ obtained from the experimental measurements. The Archard's coefficient is calculated from the Archard's law (equation (14)) considering the final measured values of time and wear volume in Table 3. $k$ is also dependent of the hardness $H$ and, as this property changes along the tests (Figure 9).

The numerical and experimental wear volume evolution for the first 300 cycles is shown in Figure 11 for different elastic-plastic material behavior. When the material is modeled to have perfectly elastic behavior, the numerical wear volume calculated (blue line) follows a perfect linear evolution with time. On the other hand, if the material behavior is modeled as elastic-perfectlyplastic the numerical wear volume evolution (red line) shows a prominent increase at the first cycles followed by a linear evolution parallel to the perfectly elastic behavior. The numerical evolution of wear, independent of the material behaviour (elastic or EPP), roughly reproduces the wear volume evolution with time. However, the experimental evolution of wear lies between the numerical results considering both limiting cases of the material behaviour. The wear evolution considering the elastic behaviour underestimates wear at the 
beginning of the test, while the EPP behaviour overestimates it although shows the wear transition experimentally observed. At longer times, the results for the elastic behaviour follow the experimental trend (not shown in the figure).

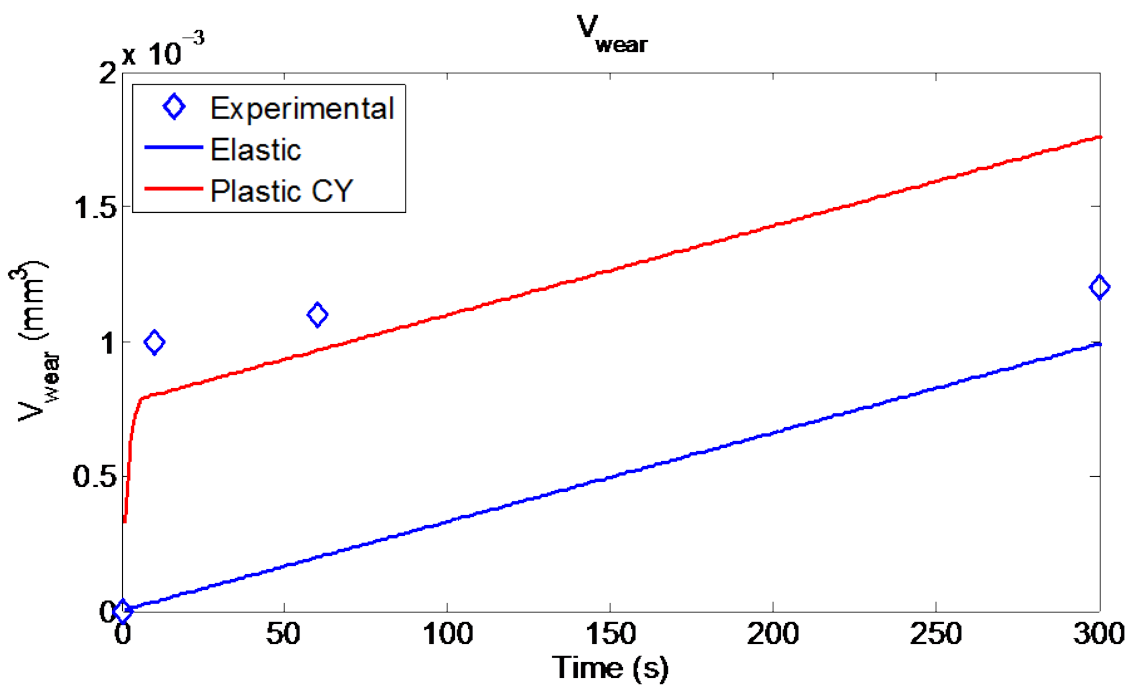

Figure 11. Time evolution of the total wear volume considering different elastic-plastic material behavior: diamonds - experimental data; blue - perfectly elastic; red - elastic-perfectly-plastic.

Figure 12 shows the experimental wear track profiles after 10 and 300 cycles (10 and $300 \mathrm{~s}$, respectively) together with the wear profiles obtained by the proposed numerical model considering EPP material behavior. The nondeformed profile of the alumina ball is also plotted for comparison purposes. The numerical profiles fit reasonably well the average shape of the experimental results. The shape of the wear track almost matches the area occupied by the ball.

a

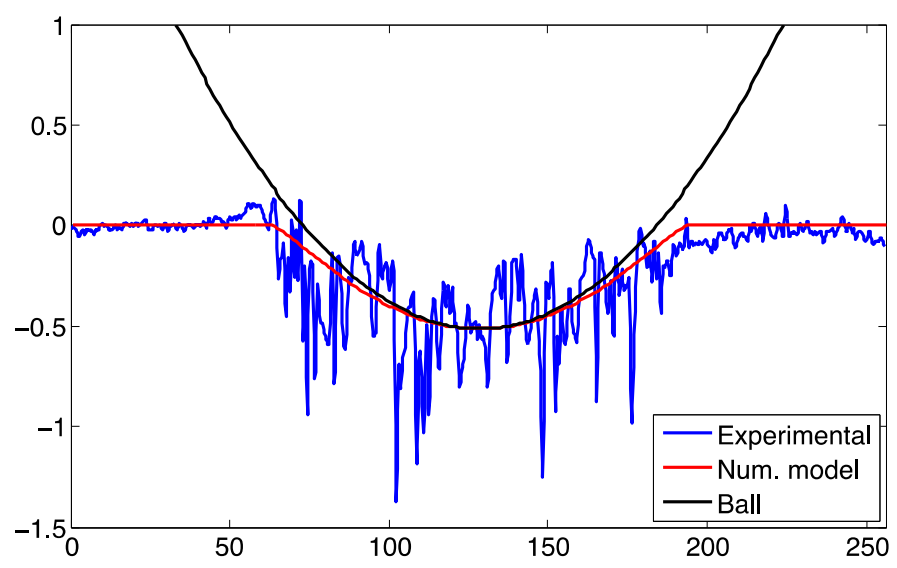


b

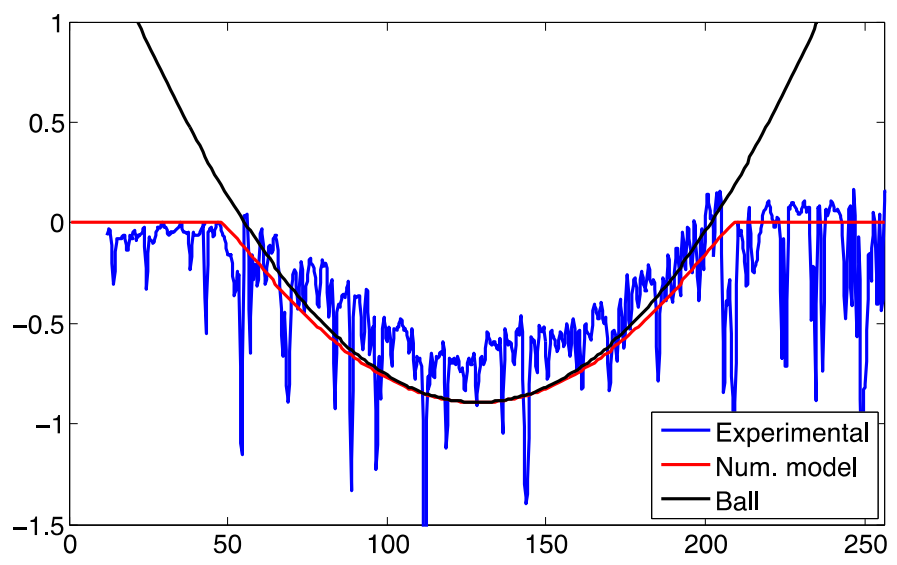

Figure 12. Experimental (blue) and numerical -elastic-perfectly plastic behavior- (red) wear track profiles and alumina ball profile (black): (a) 10 cycles; (b) 300 cycles.

\section{Discussion}

\subsection{Wear accelerated corrosion}

In a tribocorrosion system, the OCP decay at the onset of rubbing, Figure 6, is caused by the mechanical detachment of the passive film by the tribological actions, which allow exposing the underlying metal to the electrolyte thus accelerating the corrosion of the depassivated sites. Viera et al. [25] developed an electrochemical model based on the galvanic coupling between the depassivated area, the anode (i.e. plastically deformed sites/asperities of the wear track) and the still passive area, the cathode. Equation (18) describes the potential of the cathode (OCP variation with time in a tribocorrosion test) as a function of kinetic parameters (Tafel coefficients, $a_{c}$ and $b_{c}$ extracted from Figure 5) and the ratio between the anodic area, $A_{a}$, and the cathodic one, $A_{c}$.

$$
E_{c}=E_{c o r r}+a_{c}-b_{c} \log \left(\frac{i_{a} A_{a}}{A_{c}}\right)
$$

The quantification of the wear accelerated corrosion can be done by determining the anodic current coming from the depassivated zones, $i_{a}$, and applying the Faraday's law. Taking the $a_{c}$ and $b_{c}$ values from Table 2, $A_{c}$ is the electrode area $\left(2.56 \mathrm{~cm}^{2}\right)$ and $A_{a}$ the wear track area, one can determine the material loss due to the wear accelerated corrosion mechanism, Figure 13. Not surprisingly, a linear increase with time was observed because the depassivation of the whole wear track was considered. 


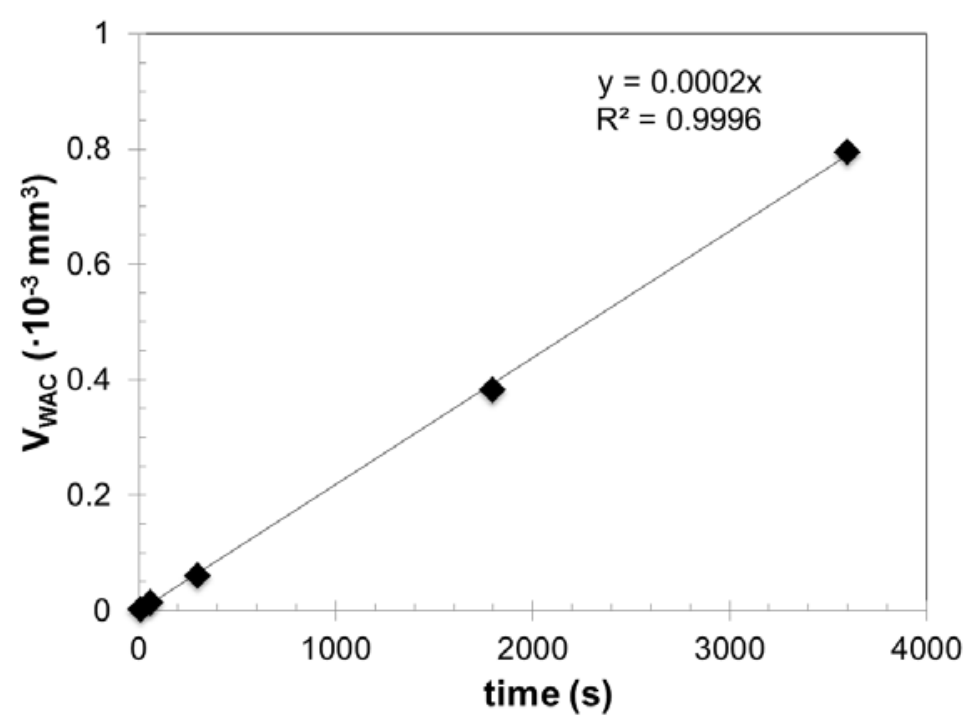

Figure 13. Wear accelerated corrosion volume $\left(V_{W A C}\right)$ as a function of the rubbing time.

However, when dealing with real surfaces with a certain roughness, it is assumed that depassivation comes from the plastic deformation of the asperities in contact. Thus, the real area of contact $\left(A_{r}\right)$ is the sum of all plastically deformed spots and corresponds to the ratio between normal load $F_{N}$ and surface hardness $H$.

The normal load is constant and equal to $5 \mathrm{~N}$ while the hardness of the surface increases with the rubbing time, as shown in Table 3 . Thus, the $F_{N} / H$ ratio, as an estimate of the real area of contact, decreases with time, Figure 10. On the other hand, the depassivated area $\left(A_{a}\right)$, which causes the wear accelerated corrosion, thus the decay in potential, can be calculated from equation (18) assuming a typical $i_{a}$ of $10 \mathrm{~mA} / \mathrm{cm}^{2}$. This value has already been reported as a common $i_{a}$ value for different metals and alloys [26]. This calculation gives an anodic area much higher than the real one, Figure 14. This is not surprising since during sliding grooves of depassivated asperities are generated and only repassivates after a certain time (short times, miliseconds, but enough to increase the depassivated area). Therefore, from two independent measurements (from hardness measurements after certain sliding time and the in-situ monitoring of the OCP decay) the real contact area and the depassivated area follow the same trend and show a constant ratio between them of around 50 times higher the depassivated area than the real one. In any case, the Hertzian area of contact lies between both values $\left(6 \cdot 10^{-3} \mathrm{~mm}^{2}\right)$. 


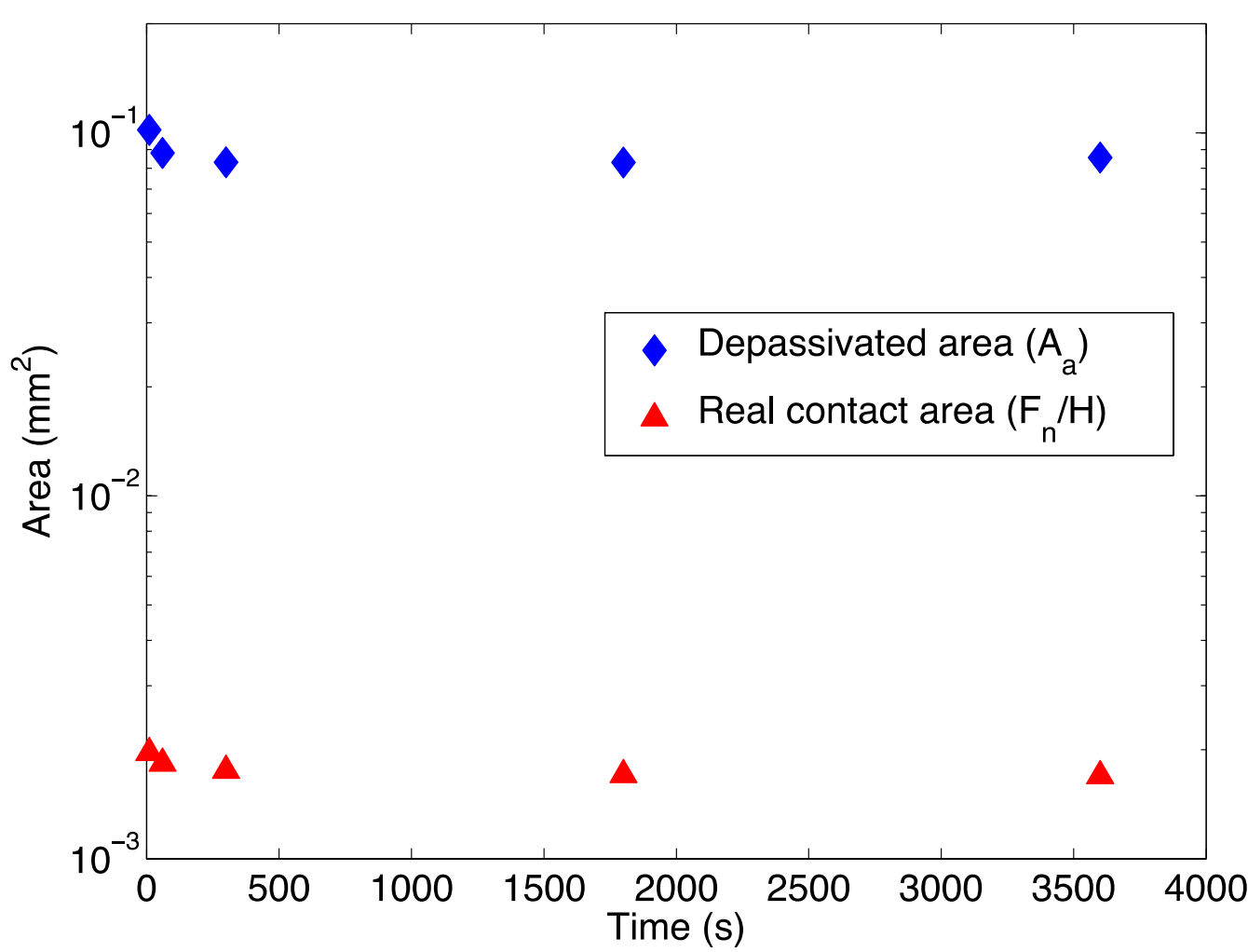

Figure 14. Representation of the real $\left(A_{r}\right)$ and the depassivated $\left(A_{a}\right)$ areas as a function of the rubbing time.

Clearly, the depassivated area corresponds to the area generated by the plastic deformation of asperities, which could be precisely determined by the numerical model, thus allowing for predicting the tribocorrosion phenomena when mechanical and electrochemical conditions are known. Further development of the model will take into account the depassivation-repassivation kinetics of the asperities in the worn profile numerically determined after each stroke.

\subsection{Numerical wear simulation}

The evolution of the experimental wear volume as a function of rubbing time, Table 3, shows two different behaviors. At short rubbing times (below 300 s) the wear volume does not follow a linear trend, while after $300 \mathrm{~s}$ of rubbing wear linearly increases as Archard predicts. Two different wear mechanisms have been accordingly proposed in the wear model described in Section 3.

During the first cycles (up to 10 cycles) the measured wear volume corresponds mainly to a gross yielding of the material under the surface. After this initial yielding process, between 10 and 300 cycles approximately, the 
material continues a process of strain hardening while the wear coefficient remains at low levels. During this period, strain hardened particles are detached and the surface suffers an abrasion process (Fig 8.a-c). Once the material at the surface reaches a critical strain, the wear mechanism changes (Fig 8.d-e) as well as the wear coefficient. This behavior could also explain the evolution with time of the depassivated area shown in Figure 10, in which after certain cycles it stabilizes.

The initial yielding process is also observed in the numerical results for the EPP material behavior (Figure 11), although the following period (between 10 and 300 cycles) with a low wear coefficient is not observed. This fact is due to that only the final value of wear volume is used for determining the wear coefficient.

The effect of the initial yielding process can also be seen in the wear profiles calculated with the numerical wear model considering the EPP material behavior. As shown in Figure 12.a, the maximum depth in the wear track reaches rapidly $0.5 \mu \mathrm{m}$ at $10 \mathrm{~s}$, due to that the contact pressure inside the contact area exceeds the yielding condition at the beginning of the test. This result corroborates that the wear profile evolution in the initial cycles is mainly due to gross yielding of the sample material that is spread out during the sliding of the ball. Then, when the contact pressures reduce below the yielding condition given by equation (12), the wear volume increases with less intensity and the maximum (of the average) wear depth does not reach $1 \mu \mathrm{m}$ at 300 cycles, Figure 12.b.

Figure 15 shows the evolution of the wear profile calculated with the wear model considering a EPP material behavior for the first 300 cycles. As previously indicated, in the first 10 cycles the wear profile formed increases rapidly, while the following cycles show a reduced wear evolution. 


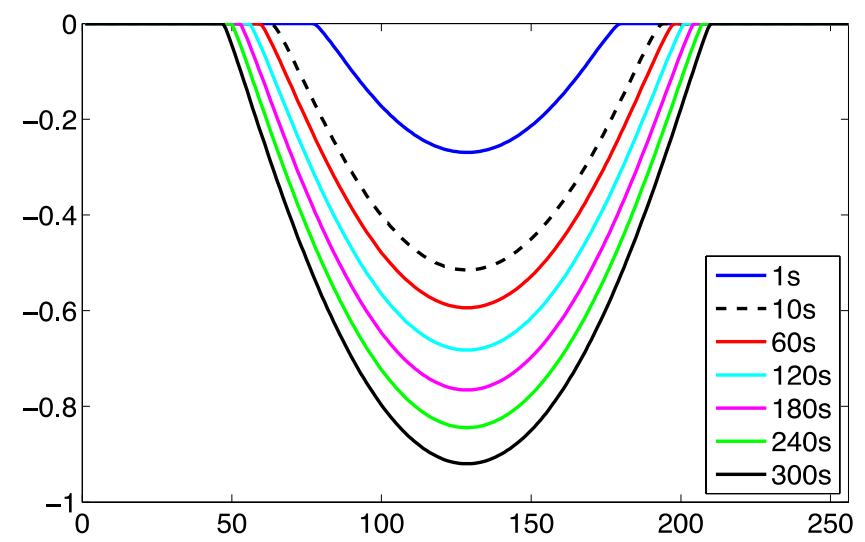

Figure 15. Evolution of the numerical -elastic-perfectly plastic behavior- wear profile up to 300 cycles.

\section{Conclusions}

The evolution of wear with time of an AISI 316L stainless steel tested under tribocorrosion conditions in a $\mathrm{NaCl}$ solution has been studied and the following conclusions can be extracted:

- Tribocorrosion is a dynamic system involving different phenomena taking place in different sites which evolve during sliding:

- During the initial cycles, the high contact pressures generate a material flow causing an increase in the worn area, which corresponds with the abrupt potential decay caused by the depassivation of the deformed surface.

- After the initial cycles, the contact pressure is low enough to stop the initial material flow. Around 300 cycles there is a transition in the wear mechanism after which the classical Archard wear model describes the wear evolution with time.

- The wear evolution with time can be described using a numerical contact model based on a Boundary Element Method (BEM) with bound constrains which allows determining the contact pressure distribution and quantifying the worn material as a function of time. The model predicts the wear profiles of the worn material and identifies the change in the plastic behavior of the material. 


\section{Acknowledgements}

This work has been funded by the Spanish Ministry of Economy and Competitiveness under the Ref. MAT2014-53764-C3-3-R and the Generalitat Valenciana under the PROMETEO program Ref. 2016/040.

\section{References}

[1] S. Mischler, Sliding Tribo-Corrosion of Passive Metals: Mechanisms and Modeling, in: B. Peter, C. Jean-Pierre, D. Dirk, F. Friedrich (Eds.), TriboCorrosion Res. Testing, Appl., ASTM international, 2013: pp. 1-18. doi:10.1520/STP1563-EB.

[2] A.I. Muñoz, N. Espallargas, 5 - Tribocorrosion mechanisms in sliding contacts, in: D. Landolt, S. Mischler (Eds.), Tribocorrosion Passiv. Met. Coatings, Woodhead Publishing, 2011: pp. 118-152. doi:http://dx.doi.org/10.1533/9780857093738.1.118.

[3] S. Mischler, A.I. Muñoz, Wear of CoCrMo alloys used in metal-on-metal hip joints: A tribocorrosion appraisal, Wear. 297 (2013) 1081-1094. doi:http://dx.doi.org/10.1016/j.wear.2012.11.061.

[4] S. Cao, S. Guadalupe Maldonado, S. Mischler, Tribocorrosion of passive metals in the mixed lubrication regime: theoretical model and application to metal-on-metal artificial hip joints, Wear. 324-325 (2015) 55-63. doi:https://doi.org/10.1016/j.wear.2014.12.003.

[5] C.B. von der Ohe, R. Johnsen, N. Espallargas, Modeling the multidegradation mechanisms of combined tribocorrosion interacting with static and cyclic loaded surfaces of passive metals exposed to seawater, Wear. 269 (2010) 607-616. doi:https://doi.org/10.1016/j.wear.2010.06.010.

[6] S. Cao, S. Mischler, Assessment of a recent tribocorrosion model for wear of metal-on-metal hip joints: Comparison between model predictions and simulator results, Wear. 362-363 (2016) 170-178. doi:http://dx.doi.org/10.1016/j.wear.2016.05.025.

[7] J.F. Archard, Contact and rubbing of flat surfaces, J. Appl. Phys. 24 
(1953) 981-988. doi:10.1063/1.1721448.

[8] D. Landolt, S. Mischler, M. Stemp, Electrochemical methods in tribocorrosion: a critical appraisal, Electrochim. Acta. 46 (2001) 39133929. doi:http://dx.doi.org/10.1016/S0013-4686(01)00679-X.

[9] P. Põdra, S. Andersson, Simulating sliding wear with finite element method, Tribol. Int. 32 (1999) 71-81. doi:http://dx.doi.org/10.1016/S0301679X(99)00012-2.

[10] E.M. Bortoleto, A.C. Rovani, V. Seriacopi, F.J. Profito, D.C. Zachariadis, I.F. Machado, A. Sinatora, R.M. Souza, Experimental and numerical analysis of dry contact in the pin on disc test, Wear 301 19-26. 301 (2013) 19-26.

[11] S. Khot, U. Borah, Finite Element Analysis of Pin-on-Disc Tribology Test, Int. J. Sci. Res. 4 (2015) 1475-1481. https://www.ijsr.net/archive/v4i4/SUB153450.pdf.

[12] F. Wang, L.M. Keer, Numerical Simulation for Three Dimensional ElasticPlastic Contact with Hardening Behavior, J. Tribol. 127 (2005) 494-502. http://dx.doi.org/10.1115/1.1924573.

[13] A. Akchurin, R. Bosman, P.M. Lugt, A Stress-Criterion-Based Model for the Prediction of the Size of Wear Particles in Boundary Lubricated Contacts, Tribol. Lett. 64 (2016) 35. doi:10.1007/s11249-016-0772-x.

[14] G.K. Sfantos, M.H. Aliabadi, A boundary element formulation for threedimensional sliding wear simulation, Wear. 262 (2007) 672-683. doi:http://dx.doi.org/10.1016/j.wear.2006.08.008.

[15] G.K. Sfantos, M.H. Aliabadi, Wear simulation using an incremental sliding Boundary Element Method, Wear. $260 \quad$ (2006) 1119-1128. doi:http://dx.doi.org/10.1016/j.wear.2005.07.020.

[16] A. Dalmau, W. Rmili, D. Joly, C. Richard, A. Igual-Muñoz, Tribological Behavior of New Martensitic Stainless Steels Using Scratch and Dry Wear Test, Tribol. Lett. 56 (2014) 517-529. doi:10.1007/s11249-014- 
0429-6.

[17] A. Dalmau, W. Rmili, C. Richard, A. Igual-Muñoz, Tribocorrosion behavior of new martensitic stainless steels in sodium chloride solution, Wear. 368-369 (2016) 146-155. doi:http://dx.doi.org/10.1016/j.wear.2016.09.002.

[18] V.G. Pina, A. Dalmau, F. Devesa, V. Amigó, A.I. Muñoz, Tribocorrosion behavior of beta titanium biomedical alloys in phosphate buffer saline solution, J. Mech. Behav. Biomed. Mater. (n.d.). doi:http://dx.doi.org/10.1016/j.jmbbm.2015.02.016.

[19] K.L. Johnson, Contact Mechanics, 1985. doi:10.1115/1.3261297.

[20] S. Björklund, S. Andersson, A numerical method for real elastic contacts subjected to normal and tangential loading, Wear. 179 (1994) 117-122. doi:10.1016/0043-1648(94)90228-3.

[21] E.A.H. Vollebregt, The Bound-Constrained Conjugate Gradient Method for Non-negative Matrices, J. Optim. Theory Appl. 162 (2014) 931-953. doi:10.1007/s10957-013-0499-x.

[22] S. Liu, Q. Wang, G. Liu, A versatile method of discrete convolution and FFT (DC-FFT) for contact analyses, Wear. 243 (2000) 101-111. doi:10.1016/S0043-1648(00)00427-0.

[23] M. Azzi, M. Paquette, J.A. Szpunar, J.E. Klemberg-Sapieha, L. Martinu, Tribocorrosion behaviour of DLC-coated 316L stainless steel, Wear. 267 (2009) 860-866. doi:http://dx.doi.org/10.1016/j.wear.2009.02.006.

[24] P.A. Dearnley, B. Mallia, The chemical wear (corrosion-wear) of novel $\mathrm{Cr}$ based hard coated $316 \mathrm{~L}$ austenitic stainless steels in aqueous saline solution, Wear. $306 \quad$ (2013) 263-275. doi:http://dx.doi.org/10.1016/j.wear.2012.09.002.

[25] A.C. Vieira, L.A. Rocha, N. Papageorgiou, S. Mischler, Mechanical and electrochemical deterioration mechanisms in the tribocorrosion of $\mathrm{Al}$ alloys in $\mathrm{NaCl}$ and in NaNO3 solutions, Corros. Sci. 54 (2012) 26-35. 
doi:10.1016/j.corsci.2011.08.041.

[26] N. Papageorgiou, S. Mischler, Electrochemical Simulation of the Current and Potential Response in Sliding Tribocorrosion, Tribol. Lett. 48 (2012) 271-283. doi:10.1007/s11249-012-0022-9. 


\section{Appendix A}

$$
\begin{aligned}
& g_{x, x}^{A}=(y+b) \ln \left(\frac{x+a+\sqrt{(x+a)^{2}+(y+b)^{2}}}{x-a+\sqrt{(x-a)^{2}+(y+b)^{2}}}\right) \\
& +(y-b) \ln \left(\frac{x-a+\sqrt{(x-a)^{2}+(y-b)^{2}}}{x+a+\sqrt{(x+a)^{2}+(y-b)^{2}}}\right) \\
& g_{x, x}^{B}=(x+a) \ln \left(\frac{y+b+\sqrt{(x+a)^{2}+(y+b)^{2}}}{y-b+\sqrt{(x+a)^{2}+(y-b)^{2}}}\right) \\
& +(x-a) \ln \left(\frac{y-b+\sqrt{(x-a)^{2}+(y-b)^{2}}}{y+b+\sqrt{(x-a)^{2}+(y+b)^{2}}}\right) \\
& g_{x, z}=\frac{y-b}{2} \ln \left(\frac{(x+a)^{2}+(y-b)^{2}}{(x-a)^{2}+(y-b)^{2}}\right)+\frac{y+b}{2} \ln \left(\frac{(x-a)^{2}+(y+b)^{2}}{(x+a)^{2}+(y+b)^{2}}\right) \\
& +(x-a)\left\{\arctan \left(\frac{y+b}{x-a}\right)-\arctan \left(\frac{y-b}{x-a}\right)\right\} \\
& +(x+a)\left\{\arctan \left(\frac{y-b}{x+a}\right)-\arctan \left(\frac{y+b}{x+a}\right)\right\}
\end{aligned}
$$

